Case Report

\title{
A spontaneous middle ear adenocarcinoma characterized by abundant eosinophilic matrix in a young male Crl:CD(SD) rat
}

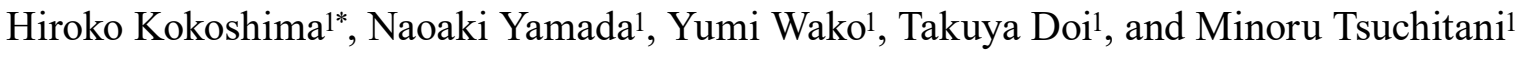 \\ ${ }^{1}$ Pathology Department, Kashima Laboratory, Nonclinical Research Center, LSI Medience Corporation, 14-1 Sunayama, \\ Kamisu-shi, Ibaraki 314-0255, Japan
}

\begin{abstract}
A mass was detected in the right tympanic cavity of a 15-week-old male Crl:CD(SD) rat. Histological examination revealed papillary or tubular proliferations of epithelial cells including ciliated cells that produce mucus and have an abundant eosinophilic matrix. The malignancy of this tumor was revealed by its destructive proliferation, cellular polymorphism, and high proliferative activity. The tumor was diagnosed as a middle ear adenocarcinoma due to its location and histological characteristics. This is the first report of a middle ear adenocarcinoma in rats and the first middle ear tumor accompanied by eosinophilic matrix observed in either humans or animals. The eosinophilic matrix was positive for periodic acid-Schiff and periodic acid-silver methenamine stains and for laminin and collagen Type IV, immunohistochemically, but negative for Congo red, which suggested that this matrix was a basement membrane substance. (DOI: 10.1293/tox.2019-0085; J Toxicol Pathol 2020; 33: 171-175)
\end{abstract}

Key words: middle ear adenocarcinoma, rat, eosinophilic matrix

In humans, middle ear tumors are rare and generally considered benign ${ }^{1}$. While there have been a small number of reports concerning middle ear tumors in $\operatorname{dogs}^{2}, 3$ and cats $^{4}$, to our knowledge there have been no such reports in rats. In this report, we describe a spontaneous middle ear adenocarcinoma in a 15 -week-old male $\mathrm{Crl}: \mathrm{CD}(\mathrm{SD})$ rat.

The animal was a 15 -week-old male $\mathrm{Crl}: \mathrm{CD}(\mathrm{SD})$ rat (Charles River Laboratories Japan, Inc., Atsugi, Japan) used in the low-dose group of a toxicity study. No relationship was suggested between the present tumor development and treatment with the test substance because the tumor was observed only in this animal of the low-dose group. The animal was housed individually in a wire mesh cage under controlled conditions $\left(21.2-23.9^{\circ} \mathrm{C}\right.$ room temperature, $41.8-$ $59.5 \%$ relative humidity, 12 -hour light/dark cycle), given a radiosterilized pellet diet (CRF-1: Oriental Yeast Co., Ltd., Tokyo, Japan) and tap water ad libitum. All experimental procedures were conducted following approval by the Institutional Animal Care and Use Committee of LSI Medience Corporation.

The animal showed no remarkable changes in clinical signs, body weight, hematology, or blood chemistry. At

Received: 11 November 2019, Accepted: 19 February 2020

Published online in J-STAGE: 22 March 2020

*Corresponding author: H Kokoshima

(e-mail: Kokoshima.Hiroko@ms.medience.co.jp)

(C)2020 The Japanese Society of Toxicologic Pathology

This is an open-access article distributed under the terms of the

Creative Commons Attribution Non-Commercial No Derivatives (by-nc-nd) License. (CC-BY-NC-ND 4.0: https:// creativecommons.org/licenses/by-nc-nd/4.0/). necropsy, a green mass filled the right tympanic cavity. No remarkable findings were observed in the other organs or tissues.

Organs, including the base of the skull containing the tumor mass, were fixed in $10 \%$ neutral-buffered formalin. The portion of skull containing the mass was decalcified using formic acid and trimmed. When trimming, it was found that the green mass extended to and destroyed the palate side bone of the tympanic bulla. The skull containing the mass was then embedded in paraffin, sectioned and stained with hematoxylin and eosin (H\&E) according to routine methods. Staining was also performed using Periodic acidSchiff (PAS), periodic acid-silver methenamine with H\&E (PAM-H\&E), and Congo red. Immunohistochemical staining was performed using antibodies against cytokeratin (WSS; DakoCytomation, Inc., Glostrup, Denmark, dilution 1:250), $\alpha$-fetoprotein (AFP; LifeSpan Biosciences, Inc., Seattle, WA, USA, dilution 1:1000), laminin (SIGMA ${ }^{\circledR}$, St. Louis, MO, USA, dilution 1:30), collagen IV (ab6586; Abcam plc, Cambridge, UK, dilution 1:100), and proliferating cell nuclear antigen (PCNA; DakoCytomation, Inc., Glostrup, Denmark, dilution 1:400). An HRP-conjugated polymer method (Histofine ${ }^{\circledR}$ Simple Stain Rat MAX PO (M); Nichirei Biosciences Inc., Tokyo, Japan) was used to detect positive signals 5 . Tissues used as positive controls include, rat tympanic cavity for cytokeratin, rat fetus for AFP, rat kidney for laminin and collagen Type IV, and rat intestine for PCNA were used. Tumor tissue from paraffin sections was processed using routine procedures for embedding into epoxy resin for transmission electron microscopy examination. Ultrathin sections stained with uranyl acetate and lead 
citrate were examined using an H-7600 electron microscope (Hitachi, Tokyo, Japan).

The tumor mass extended from the right tympanic cavity to the side of the palate (Fig. 1A). Neoplastic tissue had destroyed the bone of the tympanic bulla (Fig. 1A-C) and projected into the side of the palate. Although the tympanic cavity is normally surrounded by bone (Fig. 1A, inset), in this case the bone of the tympanic bulla was lost in places, particularly on the side of the palate. Neoplastic tissue also extended along the tympanic bulla to the cranial side (Fig. 1A). Strong mucus production was also observed.

A key histological characteristic of the present tumor was the presence of neoplastic cells which formed tubulelike structures within various amounts of eosinophilic matrix (Fig. 1A). In the eosinophilic matrix-rich area (Fig. 1A, area $\mathrm{R}$ ), the neoplastic cells were small, round to polygonal, and partly flattened with round to pleomorphic nuclei. These cells mainly formed tubular structures and partial nests (Fig. 2A), with some cells also exhibiting eosinophilic droplets in the cytoplasm. In the eosinophilic matrix-poor area (Fig. 1A, area P), there was significant papillary proliferation of the neoplastic cells. Necrosis was also observed. The neoplastic cells were different with regard to their size, columnar shape, eosin staining, and which exhibited a high nucleus/cytoplasm ratio with anisokaryosis. The neoplastic cells formed single or multi-layered epithelium and some cells were ciliated (Fig. 2B).

Immunohistochemically, the neoplastic cells showed positive staining for cytokeratin (Fig. 2C), laminin (Fig. 3C), and collagen Type VI (Fig. 3D), but not for AFP (Fig. 2D). A large number of PCNA-positive neoplastic cells were also observed (Fig. 2E and F). The eosinophilic matrix and eosinophilic droplets of the neoplastic cells were PAS-positive (Fig. 3A). Furthermore, the eosinophilic matrix was positive for PAM staining (Fig. 3B) and weakly positive for laminin and collagen Type IV (Fig. 3C, D). The matrix was negative for Congo red staining. In the transmission electron micros- copy examination, amorphous matrix lacking characteristic features such as its laminated structure, was observed in the interstitium (Fig. 4).

The epithelium lining the tympanic cavity and auditory tube, in other words, the middle ear epithelium of the rat, included both ciliated and secretory cells ${ }^{6}$. In humans, middle ear tumors can have various phenotypes, including solid, glandular or trabecular. Moreover, mucin production has occasionally been demonstrated in middle ear tumors ${ }^{1}$. Taken together, the site of development and histological characteristics of the tumor indicate that the site of origin was the middle ear epithelium. The malignancy of this tumor was revealed by its destructive proliferation, cellular polymorphism and high proliferative activity. According to the above findings, the present tumor was diagnosed as a middle ear adenocarcinoma.

To our knowledge, eosinophilic matrix has never been reported in any middle ear tumors in either humans or animals. There were morphological similarities between the present tumor and rat yolk sac carcinomas. Yolk sac carcinomas in the ears and tympanic parts of the temporal bones have also been reported in humans 7,8 . However, the present tumor was not consistent with a yolk sac tumor in that the cells were negative for AFP and the matrix did not show a laminated structure. The matrix in the present case was positive for laminin and collagen Type IV, using immunohistochemistry, and positive for PAS and PAM staining. These findings strongly suggest that the eosinophilic matrix is composed of basement membrane (BM) material ${ }^{9}$. The ultrastructural appearance of accumulated BM material has been reported to exhibit a laminated structure in some BM-producing tumors, while it is amorphous and not clearly laminated in others 9 . The presence of neoplastic cells containing eosinophilic droplets positive for PAS, laminin, and collagen Type IV, with similar features to eosinophilic matrix, suggests that these cells might be producing and secreting BM materials into the interstitium. Tumors causing

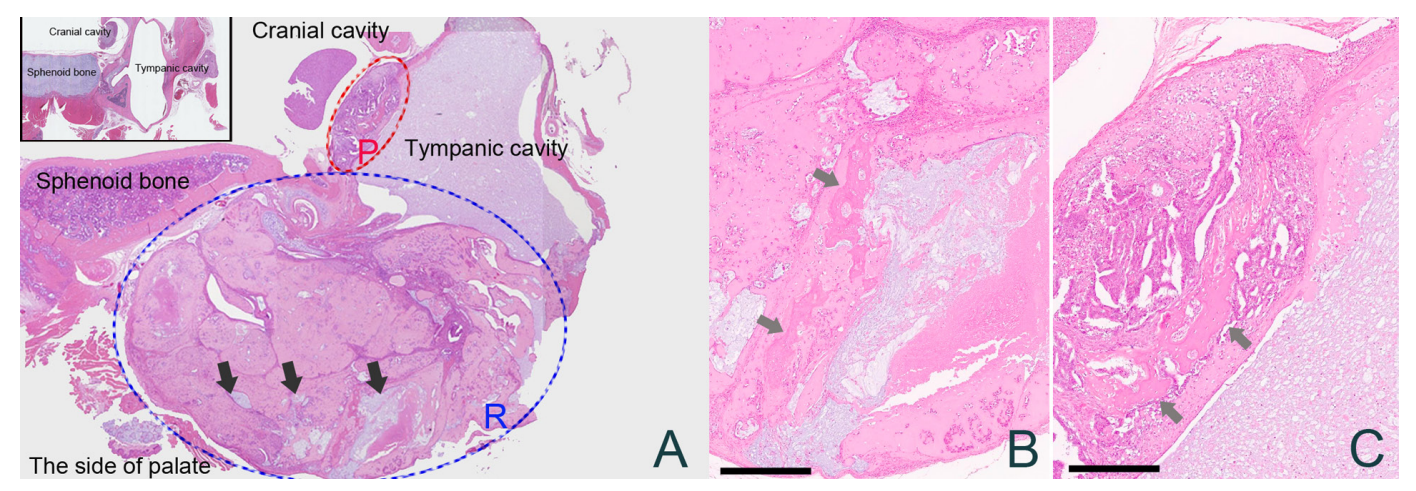

Fig. 1. Low-power view of the microscopic features of the tumor mass. The mass extends from the right tympanic cavity to the side of the palate. Although the tympanic cavity is normally surrounded by bone (inset), in this case the bone of the tympanic bulla was lost in places, particularly in the side of the palate. Mucus accumulation can be observed throughout the mass (black arrows) and the tympanic cavity is filled with mucus. Two growth patterns were observed; an eosinophilic matrix-rich area (R) and an eosinophilic matrix-poor area (P) (A). Bone fragments (gray arrows) were observed in the eosinophilic matrix-rich area (B) and the eosinophilic matrix-poor area (C). B, C: $\mathrm{Bar}=300 \mu \mathrm{m}$. 
accumulation of basement membrane materials have been reported in tissues including the thyroid gland, salivary glands, female reproductive organs, and eye $\mathrm{e}^{9-15}$.

In humans, middle ear tumors are rare and generally considered benign ${ }^{1}$. While there have been a small number of reports concerning middle ear tumors in dogs (2 adenomas $^{2,3}$ ) and cats ( 1 adenoma and 2 adenocarcinomas ${ }^{4}$ ), a malignant middle ear tumor such as the present case is considered very rare. In addition, this is the first report of a middle ear tumor in rodents.
Disclosure of Potential Conflicts of Interests: The authors declare no conflicts of interest regarding the current study.

Acknowledgments: The authors wish to thank their colleagues for their technical assistance with pathological examinations, as well as Dr. Susan A. Elmore (National Toxicology Program, National Institute of Environmental Health Sciences, National Institutes of Health) and Dr. Katsuhiko Yoshizawa (Mukogawa Women's University) for their kind counsel.

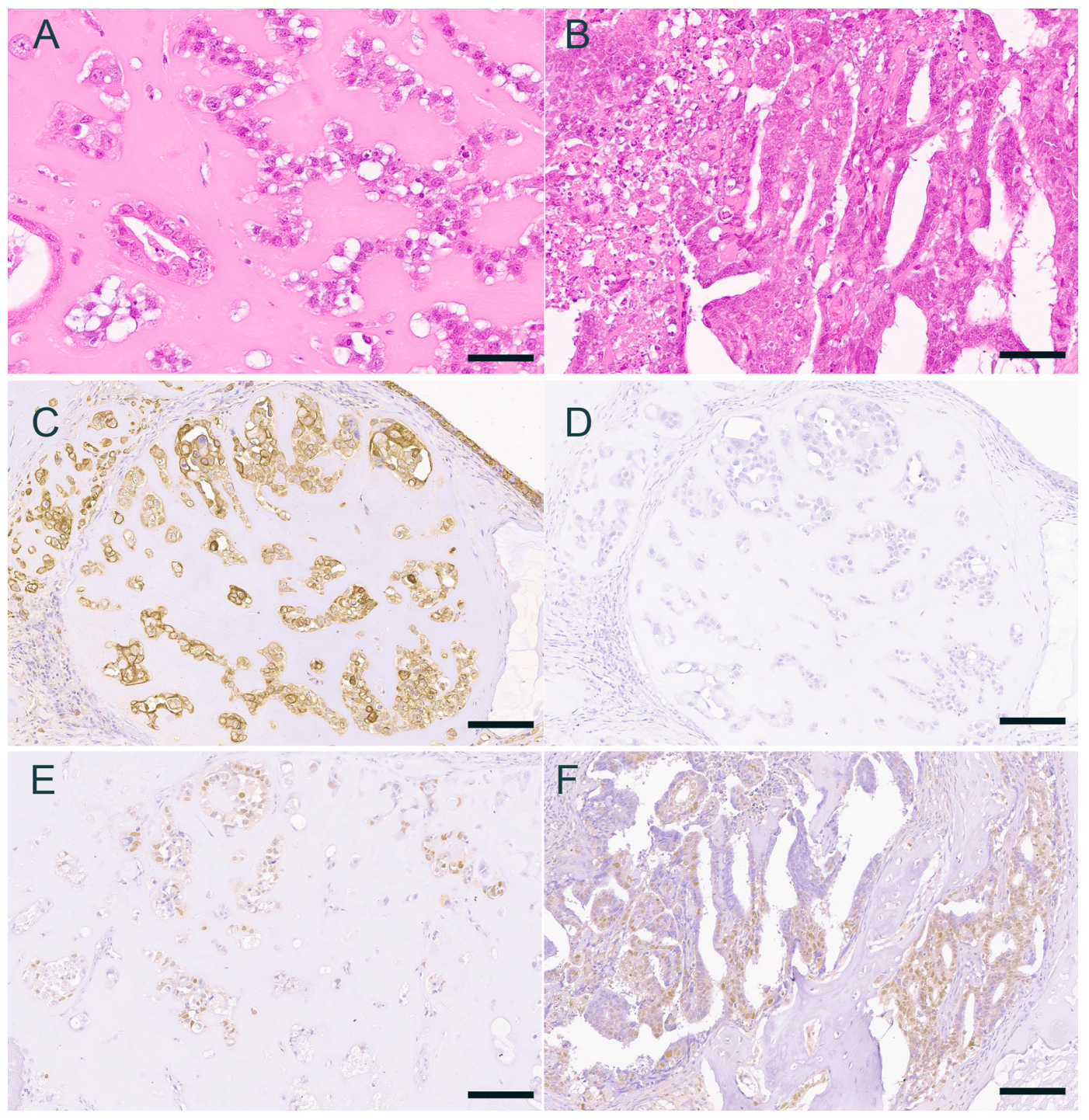

Fig. 2. H\&E staining of the eosinophilic matrix-rich area revealed that neoplastic cells mainly form tubular structures and partial nests, with some cells exhibiting eosinophilic droplets in the cytoplasm (A). H\&E staining of the eosinophilic matrix-poor area revealed neoplastic cells which were different with regard to their size, columnar shape, eosin staining, and which exhibited a high nucleus/cytoplasm ratio with anisokaryosis. The neoplastic cells form single or multi-layered epithelium and some cells were ciliated. Necrosis was also observed (B). Neoplastic cells were positive for cytokeratin (C) and negative for $\alpha$-fetoprotein (AFP) (D) in immunohistochemical staining. A large number of proliferating cell nuclear antigen (PCNA)-positive cells can be seen in both eosinophilic matrix-rich (E) and -poor areas (F). A, B: Bar $=50 \mu \mathrm{m}$. C-F: Bar $=100 \mu \mathrm{m}$. 


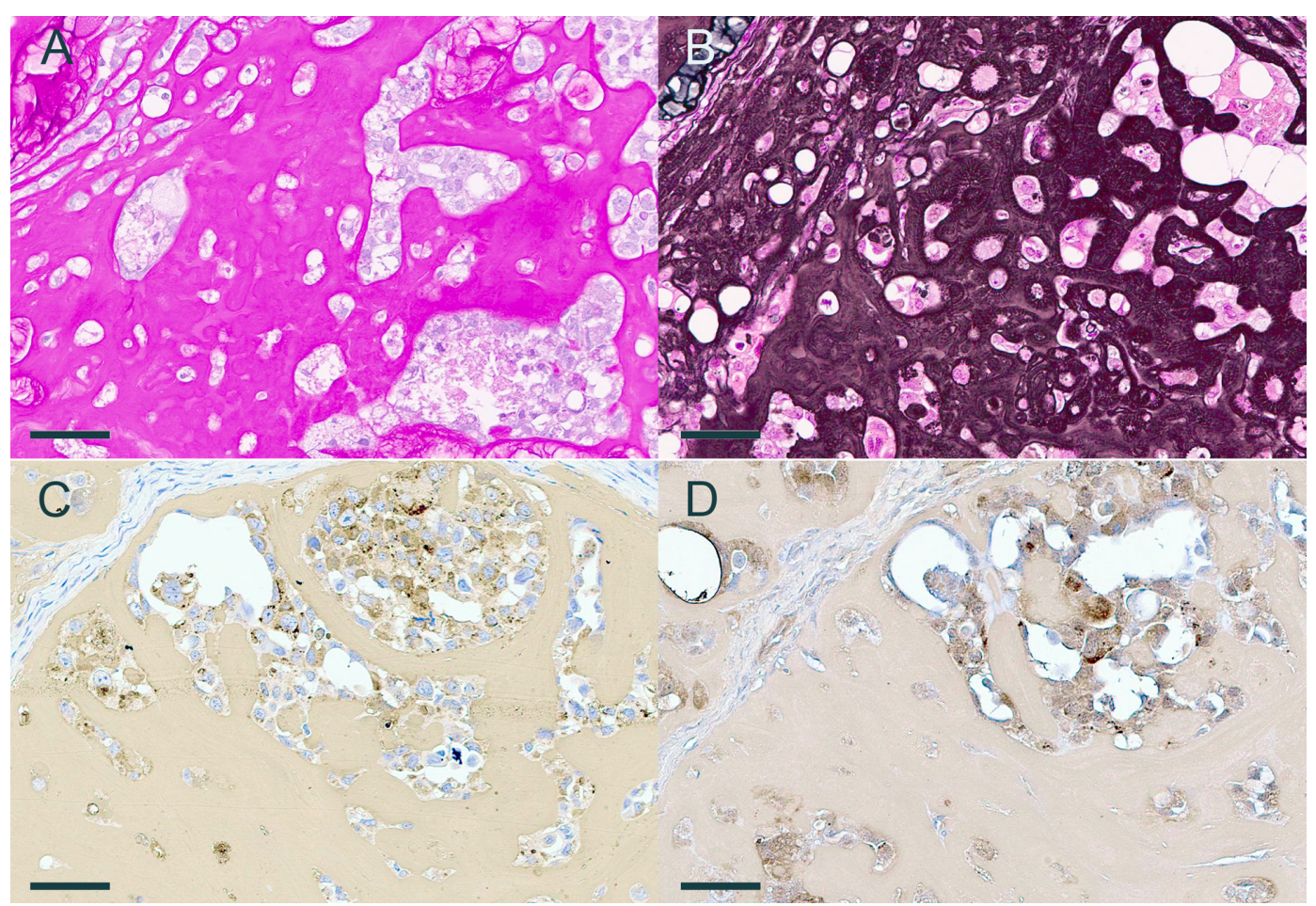

Fig. 3. Positive periodic acid-Schiff (PAS) staining can be observed in both the extracellular matrix and in eosinophilic droplets present in neoplastic cells (A). Positive periodic acid-silver methenamine (PAM) staining was observed in the extracellular matrix (B). Immunohistochemistry staining for laminin (C) and collagen Type IV (D), was weakly positive in the extracellular matrix and positive in neoplastic cells. Bar $=50 \mu \mathrm{m}$.

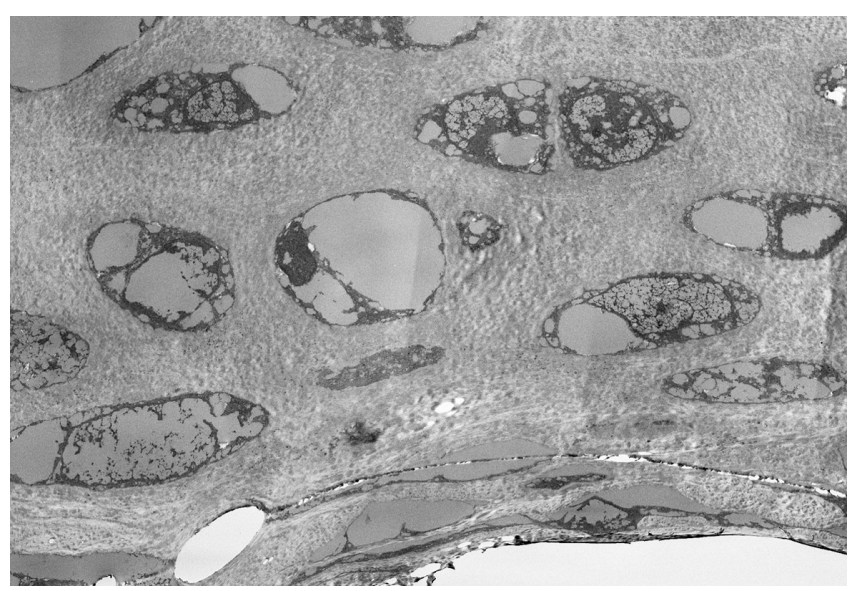

Fig. 4. Transmission electron micrograph illustrating the amorphous appearance of the matrix. Micrograph images were taken using a H-7600 electron microscope with an 5200× objective lens.

\section{References}

1. Lott Limbach AA, Hoschar AP, Thompson LDR, Stelow EB, and Chute DJ. Middle ear adenomas stain for two cell populations and lack myoepithelial cell differentiation. Head Neck Pathol. 6: 345-353. 2012. [Medline] [CrossRef]

2. Little CJL, Pearson GR, and Lane JG. Neoplasia involving the middle ear cavity of dogs. Vet Rec. 124: 54-57. 1989. [Medline] [CrossRef]

3. Hargis AM, and Thomassen RW. Adenoma of the epithelium lining the eustachian tube in a beagle dog. Vet Pathol. 17: 238-240. 1980. [Medline] [CrossRef]

4. Lucroy MD, Vernau KM, Samii VF, and LeCouteur RA. Middle ear tumours with brainstem extension treated by ventral bulla osteotomy and craniectomy in two cats. Vet Comp Oncol. 2: 234-242. 2004. [Medline] [CrossRef]

5. Furukawa S, Nagaike M, and Ozaki K. Databases for technical aspects of immunohistochemistry. J Toxicol Pathol. 30: 79-107. 2017. [Medline] [CrossRef]

6. Scarano E, Paludetti G, Frusoni F, Deli R, and Maurizi M. Morphological distribution of middle-ear epithelium in the Wistar rat: a functional hypothesis. ORL J Otorhinolaryngol Relat Spec. 59: 166-169. 1997. [Medline] [CrossRef]

7. Kaveti V, Sanjay R, and Ganeshula S. Yolk sac tumor of the ear: uncommon presentation of a rare tumor. J Clin Oncol. 28: e349-e350. 2010. [Medline] [CrossRef]

8. Fukunaga M, Miyazawa Y, Harada T, Ushigome S, and Ishikawa E. Yolk sac tumour of the ear. Histopathology. 27: 563-567. 1995. [Medline] [CrossRef]

9. Katoh R, Kakudo K, and Kawaoi A. Accumulated basement membrane material in hyalinizing trabecular tumors of the thyroid. Mod Pathol. 12: 1057-1061. 1999. [Medline]

10. Kawasako K, Doi T, Kanno T, Wako Y, Hamamura M, and Tsuchitani M. Thyroid follicular adenoma with accumulation of collagen type IV in a common marmoset (Callithrix jacchus). J Comp Pathol. 150: 71-74. 2014. [Medline] [CrossRef] 
11. Ormos J, and Halász A. Electron microscopic study of adenoid cystic carcinoma. Ultrastruct Pathol. 15: 149-157. 1991. [Medline] [CrossRef]

12. Albores-Saavedra J, Manivel C, Mora A, Vuitch F, Milchgrub S, and Gould E. The solid variant of adenoid cystic carcinoma of the cervix. Int J Gynecol Pathol. 11: 2-10. 1992. [Medline] [CrossRef]

13. Kwon TJ, Ro JY, Tornos C, and Ordonez NG. Reduplicated basal lamina in clear-cell carcinoma of the ovary: an immunohistochemical and electron microscopic study. Ultra- struct Pathol. 20: 529-536. 1996. [Medline] [CrossRef]

14. Pfaltz M, Bruckner-Tuderman L, and Schnyder UW. Type VII collagen is a component of cylindroma basement membrane zone. J Cutan Pathol. 16: 388-395. 1989. [Medline] [CrossRef]

15. Dubielzig RR, Steinberg H, Garvin H, Deehr AJ, and Fischer B. Iridociliary epithelial tumors in 100 dogs and 17 cats: a morphological study. Vet Ophthalmol. 1: 223-231. 1998. [Medline] [CrossRef] 